\title{
Molecular Structure of Thyroxine in Relation to Its Binding by Human Serum Albumin*
}

\author{
Kenneth Sterling \\ (From the Medical Service, Bronx Veterans Administration Hospital, Bron.r, .V. Y., and the \\ New York State Psychiatric Institute)
}

In previous work the existence of free thyroxine in human serum was verified by dialysis through cellophane; the concentration of the unbound hormone in normal human serum was found to approximate one-thousandth of the total thyroxine (1). This direct measurement of free thyroxine was in reasonable agreement with the theoretical value computed from data on the per cent of total thyroxine bound to albumin in serum and from the binding constants for the interaction between thyroxine and human serum albumin (2, 3 ). This theoretical value of expected free thyroxine concentration was in accordance with the earlier calculations of Robbins and Rall (4), based upon Lein's equilibrium dialysis studies of the interaction between thyroxine and bovine serum albumin (5).

Recent studies of the binding of thyroxine by albumin in our own (6) and in other laboratories (7-11) have indicated the existence of a single strong binding site on the protein molecule rather than a primary class of four equal binding loci, as originally proposed $(2,3)$. The data, to be reported separately in detail (6), suggest that the albumin molecule possesses a single strong binding site with an association constant approximating 500,000 , a secondary class of three or four sites of intermediate affinity for thyroxine, and a tertiary class of many weaker sites. This conceptual revision does not necessitate appreciable alteration of the calculations of expected concentration of free thyroxine in serum $(1,3)$. There are approximately 10,000 albumin molecules to one of thyroxine in human serum. Under these circumstances of low thyroxine to albumin ratio (i.e., at theoretical thyroxine: albumin ratios approaching zero), the original model of a primary class of

\footnotetext{
* Submitted for publication January 24, 1964 ; accepted May 7, 1964.

Supported in part by grant AM-02770-04 and 05 from the U. S. Public Health Service.
}

four equal loci with association constants of 110 ,000 (2) should bind about the same amount of thyroxine as a single site with an association constant approximating 500,000. Moreover, the current model does not affect the comparative position of thyroxine in relation to binding of other small molecules. Thus, albumin binds thyroxine somewhat more tightly than it binds the anionic dye. methyl orange (12), or tryptophan (13) but much less tightly than it binds the free fatty acids of serum (14).

The present report describes investigation of the features of the molecular structure of thyroxine requisite for firm binding by albumin. Equilibrium dialysis studies of the interaction between human serum albumin and $\mathrm{I}^{\mathbf{1 3 1}}$-labeled thyroxine were carried out in the presence and in the absence of various nonradioactive compounds as competing ligands.

\section{Materials and Methods}

The I I11-labeled thyroxine ${ }^{1}$ used in this study was stabilized with cysteine in a propylene glycol solution. The material was subjected to descending chromatography as previously described (3) and discarded if the iodide contamination exceeded $5 \%$. The sources of the nonradioactive thyroxine, its analogues, and various other compounds used in competition studies are given in the Appendix.

Equilibrium dialysis method. The equilibrium dialysis procedure was the same as that previously described in detail $(2,3)$, except as noted in the following abbreviated account. The $0.1 \mathrm{~g}$ per $100 \mathrm{ml}\left(1.45 \times 10^{-5} \mathrm{M}\right)$ albumin solution in a cellophane dialysis bag was suspended in an equal volume of potassium phosphate buffer, $\mathrm{pH} 7.4$, 0.15 ionic strength. ${ }^{2}$ Graded increments of I $^{131}$-labeled

\footnotetext{
${ }^{1}$ Supplied by Abbott Laboratories, North Chicago, Ill.

2 Because of limited solubility of three of the analogues, L-thyroxine O-methyl ether, thyroxamine, and the $N$ acetyl-4'-acetoxy methyl ketone derivative of thyroxine, the use of pH 7.4 buffer was not optimal. Instead, Trissodium chloride buffer $(0.05 \mathrm{M}$ Tris, $0.1 \mathrm{M} \mathrm{NaCl})$ at pH 8.6 was employed, with the addition of $10 \%$ ethanol or $10 \%$ propylene glycol. The Scatchard plots (15-17)
} 


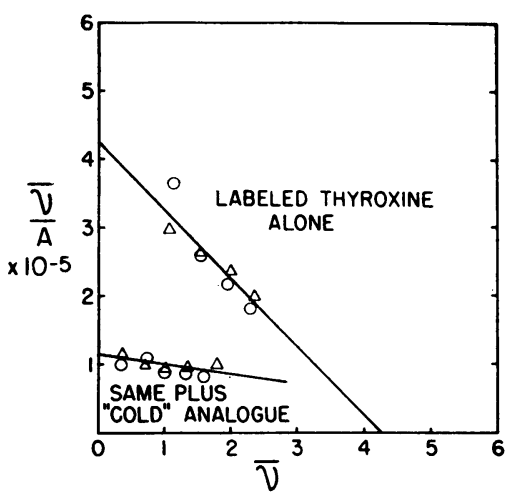

Fig. 1. Competition STUdy BetWeen labeled thyROXINE AND “COLD" TETRAIODOTHYROACETIC ACID. The triangles represent points where $I^{131}$-thyroxine was added to the protein solution inside the dialysis bag, and the circles represent points where the tracer was added to the buffer outside. The close approximation of the pairs of points signifies satisfactory equilibration. $\bar{\nu}=$ moles $T_{4}$ bound/mole albumin; $A=$ the concentration of free $T_{4}$.

thyroxine were added to a series of tubes in duplicate, the tracer being added inside the bag in one instance, outside the bag in the other. The total thyroxine concentration in the system ranged from $6.45 \times 10^{-6} \mathrm{M}$ to $3.2 \times 10^{-6} \mathrm{M}$ in most of the studies. At the end of an appropriate period (about 16 hours) of mechanical shaking for equilibration in a water bath at $37^{\circ} \mathrm{C}$, samples from each compartment were counted. The fraction bound was obtained from (counts per minute inside - counts per minute outside)/ total counts per minute. The values for duplicate tubes were in agreement if equilibrium was achieved.

The data on fraction bound were then employed to obtain binding constants as described by Scatchard (15-17). The symbols for the Scatchard formulation were as follows:

$\bar{\nu}=$ moles $\mathrm{T}_{4}$ (thyroxine) bound $/$ mole albumin

$A=$ the concentration of free $T_{4}$ (theoretically, the "activity" of $\mathrm{T}_{4}$ )

$\mathrm{n}=$ the number of binding sites on the albumin molecule available for thyroxine, i.e., the maximal value of $\bar{\nu}$

$\mathrm{k}=$ the apparent association constant (liters per mole), which is the equilibrium constant in the direction of complex formation, i.e., the reciprocal of the classical dissociation constant of Arrhenius.

These quantities were related in the equation derived by Scatchard from the law of mass action: $\bar{\nu} / \mathrm{A}=\mathrm{kn}-\mathrm{k} \bar{\nu}$.

From the protein concentration employed, the thyroxine concentration added, and the fraction bound, the value

obtained with the added organic solvents did not differ appreciably from control studies run simultaneously without the solvents at $\mathrm{pH}$ 8.6. Moreover, where solubility presented no problem, thyroxine control studies and thyroxine plus analogue studies run at $\mathrm{pH} 7.4$ and 8.6 showed quantitatively insignificant differences in this $\mathrm{pH}$ range, unless the analogue lacked two iodine atoms ortho to the $4^{\prime}$-hydroxyl group, e.g., triiodothyronine $(2,3,6)$. for $\bar{\nu}$ was computed for each of the tubes of the study. The value for $A$, the free thyroxine concentration, was obtained from counts per minute per milliliter outside by employing the known specific activity of thyroxine added.

Where a single class of binding sites exists, a plot of $\bar{\nu} / \mathrm{A}$ against $\bar{\nu}$ gives a straight line (Figures 1 and 2). The extrapolations to the axes were employed to obtain binding constants. With increasing thyroxine concentration, binding sites are saturated; the intercept on the $\bar{\nu}$ axis is $n$, the maximal number of binding sites. The intercept on the $\bar{\nu} / \mathrm{A}$ axis is $\mathrm{kn}$, as can be seen from the equation where the expression $k \bar{\nu}$ drops out as $\bar{\nu}$ approaches zero and $\bar{\nu} / \mathrm{A}$ approaches $\mathrm{kn}$.

Recent studies to be reported separately (6) include additional points to the left of any illustrated in Figures 1 and 2, i.e., total thyroxine concentrations below $6.45 \times 10^{-6} \mathrm{M}$ equilibrated with $0.1 \mathrm{~g}$ per $100 \mathrm{ml}$ albumin solutions $\left(1.45 \times 10^{-5} \mathrm{M}\right)$ within the dialysis bags. The additional points revealed an undoubted upward swing of the curve quite close to the ordinate. This deviation from linearity is interpreted by us to be due to the existence of a single strong binding site rather than to apparent minute but quantitatively insignificant contamination with thyroxinebinding alpha globulin (TBG) (6).

Most of the work presently reported antedated these observations in our laboratory. Therefore, all Scatchard plots have been handled in conformity with the original interpretation of a single class of four binding loci with $k_{1} \cong 1 \times 10^{5}$. The observations and interpretations are not invalidated by the revised model of the thyroxinealbumin interaction (cf. below and Discussion).

The only significant departure from the previous description $(2,3)$ was the use of a different albumin preparation for much of the work. The American Red Cross supplied albumin as a dry powder of Cohn Fraction V, as well as the previously available ampules of the pasteurized $25 \%$ solution, stabilized by the addition of sodium caprylate and sodium acetyltryptophanate. The use of the dry powder obviated the need for dialysis and passage through Amberlite MB-1 resin, previously employed to remove the preservatives. The dry powder and the deionized, dialyzed protein gave identical results. All albumin preparations studied to date have revealed contamination with a minute amount of protein with the electrophoretic mobility

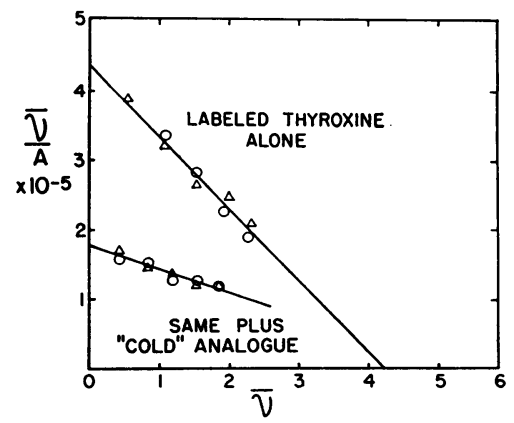

Fig. 2. Competition study Between labeled thyROXINE AND "COLD" TETRACHLORTHYRONINE. Significance of triangles, circles, and abbreviations same as in Figure 1. 
of TBG, provided minimal amounts of $I^{131}$-thyroxine were employed (6). However, the greatest possible amount of TBG contamination demonstrable in amorphous albumin (or in crystalline human mercaptalbumin) appeared insufficient to have a detectable effect upon the Scatchard plot (6).

The present work consisted of competition studies between I ${ }^{131}$-labeled thyroxine and nonradioactive compounds as competing ligands. In all studies, a control standard equilibrium dialysis experiment was run simultaneously with the study in which the "cold" competitor had been added. The diminution in binding caused by the competing ligand (Figures 1 and 2) was employed to calculate the association constant of the competitor for the theoretical four primary binding sites for thyroxine on the protein molecule. The following equation from Edsall and Wyman (18) was employed:

$$
\mathrm{k}_{\mathrm{B}}=\frac{1}{(\mathrm{~B})}\left(\frac{\mathrm{k}_{\mathrm{A}}}{\mathrm{k}_{\mathrm{A}}^{\prime}}-1\right)
$$

where

$\mathbf{k}_{\mathrm{A}}=$ the association constant for labeled thyroxine alone $\mathbf{k}_{\mathrm{A}}{ }^{\prime}=$ the thyroxine association constant in the presence of the "cold" competing ligand at a specific concentration

(B) $=$ the concentration of the competing ligand

$\mathrm{k}_{\mathrm{B}}=$ the association constant of the competing ligand for the theoretical four primary binding sites for thyroxine.

It can readily be seen that if the cold material had no effect, $k_{A}{ }^{\prime}$ would be the same as $k_{A}$, and the quotient $k_{A} / k_{A}{ }^{\prime}$ would be 1 ; thus, $k_{B}$ would be 0 , indicating no binding.

The competition studies were done at different concentrations of the competing ligand, until one or more sufficiently depressed linear plots were obtained. The studies were continued until reasonable agreement of computed $k_{B}$ values was found; this required at least three or four studies of the type illustrated (Figures 1 and 2) in most instances.

Figures 1 and 2 illustrate that the lower curves representing thyroxine plus the "cold" analogue would intersect the abscissa at values well above 4.0 if extended as straight lines. This is interpreted as the effect of the higher class of weaker binding sites. Limited solubility of thyroxine precludes accurate determination of the higher class at $\mathrm{pH}$ 7.4 , but at $\mathrm{pH} 9.8$, where points farther to the right could be determined accurately, a definite flattening of the Scatchard plot was observed (Figure 5 of reference 3) (6). The low flat curves obtained for $\mathrm{I}^{131}$-thyroxine in the presence of the analogue were employed to obtain a hypothetical $\mathrm{k}_{\mathrm{A}}{ }^{\prime}$ by dividing the $\mathrm{k}^{\prime}{ }_{\mathrm{A}} \mathrm{n}$ value of the ordinate intercept by 4 , regardless of the fact that the extrapolated line might intersect the abscissa at a higher number than 4 . Initially, this was considered to represent the competition of the nonradioactive ligand for the originally proposed four primary binding sites on the albumin molecule. In the light of the concept of a single strong site and three or four loci of intermediate affinity for thyroxine (6), this formulation is still considered reasonable to obtain relative $k_{B}$ values for the compounds studied. The absolute $k_{B}$ values have been estimated (cf. Discussion) and included in Tables I to III as "true" $k_{B}$ values.

\section{Results}

1) Compounds with a single aromatic ring. In contrast with the value of 100,000 for thyroxine, the calculated association constants for the compounds with a single aromatic ring were below 1,000 with two exceptions (Table I). The only values over 1,000 were observed with 2,4-dinitrophenol and salicylate, two compounds that have previously been shown to displace thyroxine from its binding by prealbumin $(19,20)$. Diiodotyrosine, with reactive groups similar to those of thyroxine, was found to be very weakly bound. It was inferred, therefore, that the diphenyl ether (thyronine) structure is essential for firm binding.

2) The effect of alterations in the iodine substituents. Table II lists the results of studies of some derivatives that possess the thyronine nucleus but lack one or more of the four iodine atoms of thyroxine. The propionic acid derivative of triiodothyronine was bound more firmly than triiodothyronine itself. Tetrachlorthyronine, with chlorine in place of iodine atoms, was found to have an association constant only one-ninth that of thyroxine. The nitro derivatives were even more weakly bound. Thyronine derivatives with two, one, and no iodine atoms revealed progressively weaker binding; the very low association constant for thyronine, being less than 1,000 , was the lowest for any compound with the thyronine nucleus. It was, therefore, concluded that not only is the thyronine nucleus essential for firm binding by albumin, but also it must be halogenated, and optimal interaction requires the tetraiodinated compound.

3) Importance of the various reactive groups of thyroxine. To evaluate the various reactive groups of the thyroxine molecule, a special series of thyroxine analogues was examined in competition studies (Table III). The importance of the dissociable hydroxyl (phenolate) group in the interaction was explored by using a compound with a nonionizable substituted group, namely, the O-methyl ether of thyroxine (methoxy-thyroxine), studied as a competing ligand. The methyl ether derivative had an association constant approximating 10,000 or only one-tenth that of thyroxine. 
TABLE I

Compounds with a single aromatic ring

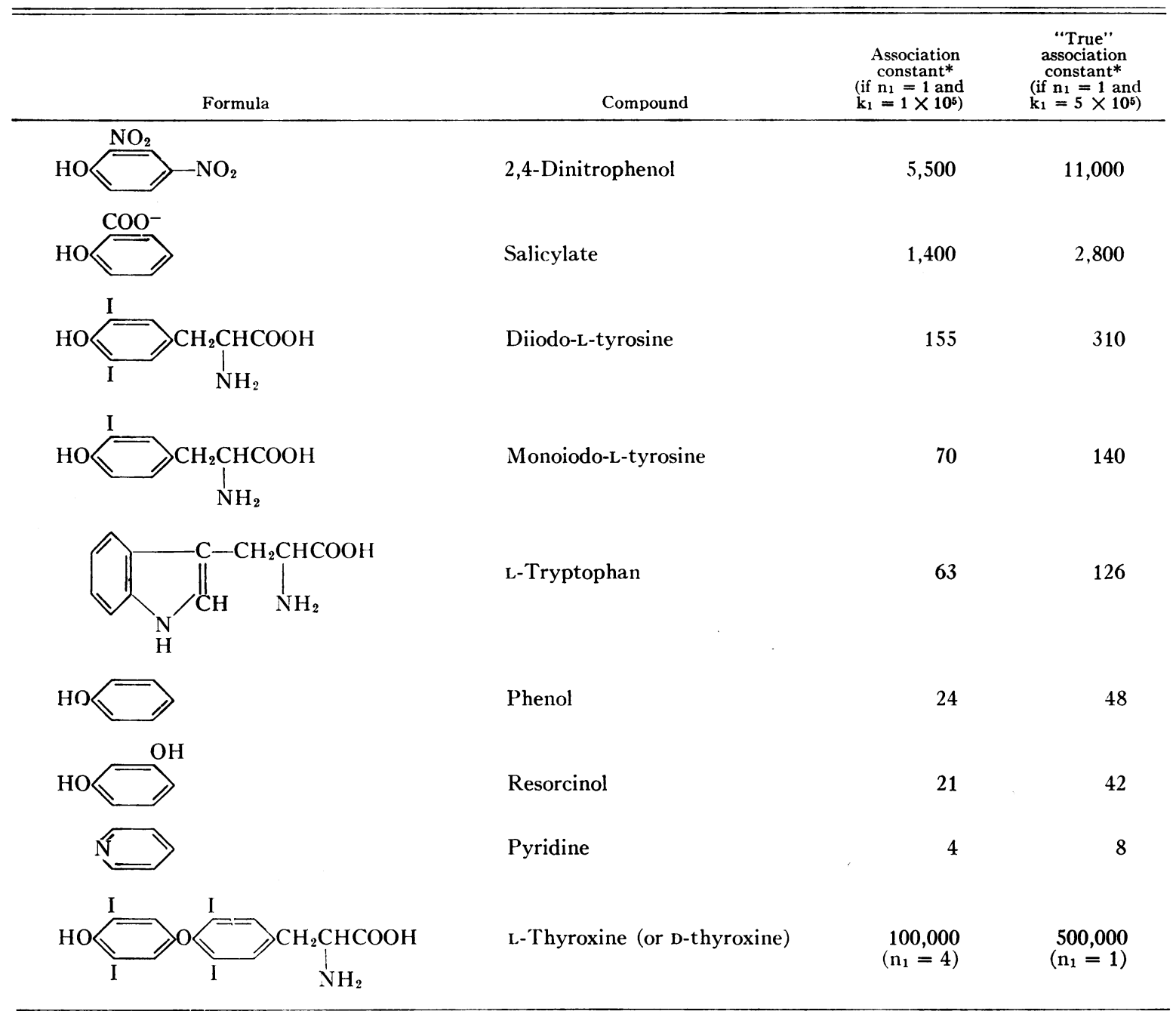

${ }^{*} \mathrm{n}=$ the number of binding sites on the albumin molecule available for thyroxine; $\mathrm{k}=$ the apparent association constant.

The replacement of the hydroxyl group by a methyl ether represents an alteration of structure that could have effects in addition to the elimination of the charged group. Nevertheless, the inference regarding the significance of this anionic hydroxyl group in binding is consistent with conclusions advanced previously, based upon the comparative behavior of thyroxine and triiodothyronine $(2,3)$. At $\mathrm{pH} 7.4$ triiodothyronine had approximately one-tenth as great an association constant as thyroxine. This behavior by triiodothyronine was attributed to one-tenth as great an extent of ionization of the phenolic hydroxyl group, $8 \%$ ( $\mathrm{pK}^{\prime}$ of 8.45 ), as compared with $82 \%$ for thy- roxine ( $\mathrm{pK}^{\prime}$ of 6.73 ). However, at $\mathrm{pH} 8.6$, with greater dissociation of the hydroxyl group, triiodothyronine was found to be more firmly bound by albumin than at $\mathrm{pH} 7.4(2,3,6)$.

Modifications of the alanine side chain resulted in variable reductions in affinity. The decarboxylated derivative, thyroxamine, was found to have a low association constant, which suggests that the carboxyl group has an important role in binding. The limited solubility of thyroxamine made studies with it difficult, and the data obtained must be considered approximate values. Tetraiodothyropropionic acid, which differs from thyroxine only in lacking the $-\mathrm{NH}_{2}$ group, showed a rela- 
tively slight reduction of binding (association tween albumin and tetraiodothyroacetic acid, and constant of 80,000$)$. This indicates that the car- a still lower constant $(36,000)$ when the ligand boxyl group is more important than the amino was tetraiodothyroformic acid. It is noteworthy group. The significance of the three-carbon length that the $N$-acetyl-acetoxy-methyl ketone, a comof the side chain was suggested by a lower associ- pound with all reactive groups blocked, still posation constant $(50,000)$ for the interaction be- sessed an association constant of approximately

TABLE II

The effect of alterations in the iodine substituents

\begin{tabular}{|c|c|c|c|}
\hline Formula & Compound & $\begin{array}{c}\text { Association } \\
\text { constant } \\
\text { (if } \mathrm{n}_{1}=1 \text { and } \\
\left.\mathrm{k}_{1}=1 \times 10^{5}\right)\end{array}$ & $\begin{array}{c}\text { "True"" } \\
\text { association } \\
\text { constant } \\
\text { (if } \mathrm{n}_{1}=1 \text { and } \\
\left.\mathrm{k}_{1}=5 \times 10^{5}\right)\end{array}$ \\
\hline
\end{tabular}

$\longrightarrow \mathrm{CH}_{2} \mathrm{CH}_{2} \mathrm{COOH} \quad 3,5,3^{\prime}$-Triiodothyropropionic aci<smiles>CO</smiles><smiles>NC(Cc1ccc(I)c(Oc2ccccc2)c1)C(=O)O</smiles><smiles>NC(C(=O)O)c1ccc(Cl)c(Cl)c1</smiles><smiles>CC(C)c1ccc(Oc2ccc(C(N)C(=O)O)cc2)cc1O</smiles><smiles>NC(Cc1ccc(OC(=O)O)cc1)C(=O)O</smiles><smiles>NC(Cc1ccc([N+](=O)[O-])cc1)C(=O)O</smiles><smiles>NC(Cc1cccc(O)c1)C(=O)O</smiles><smiles>NC(C(=O)O)c1ccc(Oc2ccccc2)cc1</smiles><smiles>NC(C(=O)O)c1ccc(Oc2ccccc2)cc1</smiles><smiles>NC(Cc1ccc(O)cc1)C(=O)O</smiles>

Tetrachloro-DL-thyronine

11,700

23,400

3'-Isopropyl-3,5-diiodo-L-thyronine

7,600

15,200

$3^{\prime}, 5^{\prime}$-Dinitro-3,5-diiodo-L-thyronine

5,200

10,400

Tetranitro-DL-thyronine

3,300

6,600

3,5-Diiodo-DL-thyronine

3,200

6,400

3-Monoiodo-DL-thyronine

2,530

5,060

DL-Thyronine

330

660 
Importance of the various reactive groups of thyroxine

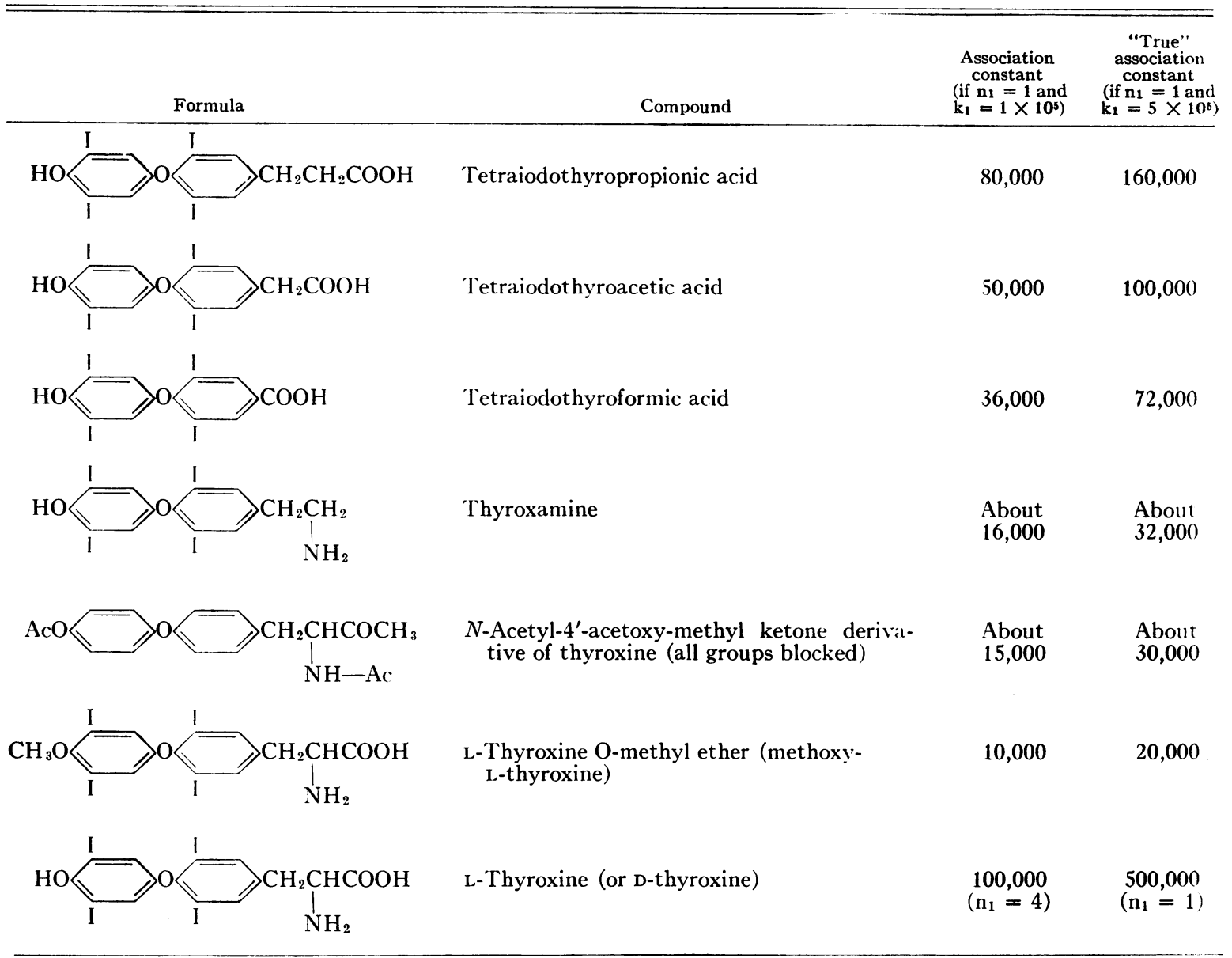

15,000. Due to limited solubility, the value obtained must be regarded as an approximation.

It was concluded that in addition to the previously reported interaction $(2,3)$ between the anionic phenolate group of thyroxine and cationic groups on the protein molecule, there is an additional interaction of the carboxyl group of the alanine side chain.

\section{Discussion}

The values presented as association constants for the compounds tested should be regarded as having relative rather than absolute quantitative significance, since the computations assumed competition for a single class of four equivalent thyroxine-binding loci on the albumin molecule. The present view of a single strong site, and a secondary class of three or four sites of inter- mediate affinity for thyroxine, would require some revision of computations and experimental design as well, for absolute rather than relative $\mathbf{k}_{B}$ values. Adjusted $k_{B}$ values ("true" $k_{B}$ values) are given in the tables, based upon repetition of the competition studies with three selected readily available analogues, one for each table. The compounds, L-tryptophan, 3,5,3'-triiodo-L-thyronine, and tetraiodothyropropionic acid, were selected as representative of the groups in Tables I, II, and III, respectively, and the studies were repeated employing three additional thyroxine concentrations below $6.45 \times 10^{-6} \mathrm{M}$. The association constants computed employing the current model of a single binding site yielded a mean value approximately twice the results previously obtained. Consequently, it was considered reasonable to append the column of "true" $k_{B}$ values, the detailed evidence 
for which is to be reported separately (6). In any case, the precise absolute values of the association constants should not affect the interpretations regarding the structural characteristics of the thyroxine molecule requisite for firm binding by albumin.

The competition studies described above concern only the interaction of thyroxine with its specific binding sites on the protein molecule; it is entirely possible that some of the compounds tested might be bound by albumin at other loci. Some error could theoretically be introduced on this account if the amount of nonradioactive competitor bound at other sites were to diminish the concentration of the unbound ligand appreciably. In actuality, the error so introduced should usually be small in magnitude, as exemplified by the triiodothyronine association constant obtained by the present method compared with direct measurements employing I ${ }^{131}$-labeled triiodothyronine (2, $3,6)$. Nevertheless, this uncertainty imposes a limitation upon the information available from studies with nonradioactive competing ligands. This may be exemplified by the findings with $\mathrm{I}^{131}$ labeled tetraiodothyropropionic acid, which have shown it to be more rather than slightly less firmly bound than thyroxine $(11,6)$. This may well be due to the firm binding of the propionic acid derivative at loci on the albumin molecule that are weaker binding sites for thyroxine (6). Such an interpretation suggests that the amino group of thyroxine may actually tend to inhibit binding at some loci, a concept compatible with our hypothesis of the role of cationic groups in the binding loci on the albumin molecule (vide infra).

Analogous results with the present competition studies are evident in Table II, which shows the propionic acid derivative of triiodothyronine more firmly bound than triiodothyronine itself.

The evidence presented indicates the following characteristics of the thyroxine molecule as being essential to its firm binding by albumin: 1) the diphenyl ether (thyronine) structure, 2) the iodine atoms with an optimal number of four, 3 ) the dissociated (anionic) phenolic hydroxyl group, and 4) the alanine side chain, and particularly its carboxyl group.

The specific sites on albumin where thyroxine is bound are not known, nor are the loci yet determined for most of the small molecules bound by albumin. Tryptophan (13) has been shown to interact with the $N$-terminal aspartic acid residue of albumin that is part of its single site of binding. No information has been provided regarding the loci at which albumin binds free fatty acids; a primary class of two binding sites for the fatty acids was reported by Goodman (14) with secondary and tertiary classes of loci as well. It was previously shown in our laboratory (3) that removal of the free fatty acids by isoöctane extraction of human serum albumin resulted in no alteration in the number of primary binding sites for thyroxine, since $\mathrm{n}$ remained the same. A somewhat higher association constant was observed when isoöctane-extracted albumin was compared with the starting material; addition of 2 moles of palmitate per mole of protein resulted in a curve indistinguishable from the original.

Our previous report (3) suggested that the epsilon amino groups of lysine residues of albumin may be important in the interaction. At very strongly alkaline reaction ( $\mathrm{pH} 10.9$ and 11.2) at which the free amino groups of the protein lose protons, the binding was found to be markedly reduced. Blocking of the free amino groups by acetylation also resulted in marked diminution of the binding. From this information, it was inferred that an interaction occurred between the dissociated (anionic) phenolic hydroxyl group of thyroxine and cationic groups on the protein molecule, probably epsilon amino groups of lysine residues. However, this specific hypothesis cannot be considered proven, since the loss of protons or the acetylation of free amino groups would cause the protein molecule to have a greater net negative charge. The reduction of affinity between a more negatively charged protein molecule and the thyroxine anion could be conceived without any necessary inference regarding free amino groups as loci.

Conceding that the role of lysine residues is provisional rather than established, one must view the question in the context of available information that albumin possesses approximately $55 \mathrm{ly}$ sine residues per molecule (21). A priori there is nothing that points to any particular individual free cationic groups. In the light of the present evidence, one may speculate that the loci concerned actually include a pair of free cationic groups, possibly lysyl epsilon amino groups-one each 
interacting with the phenolate and carboxyl groups of thyroxine. Intervening between the cationic groups, one may suppose a specific amino acid sequence, which could include aromatic amino acids with hydrogen bonding or van der Waals attraction for the iodinated diphenyl ether structure of thyroxine. Although various models of an albumin-binding locus may be considered, further studies will be required for verification of the hypotheses.

\section{Summary}

1. Equilibrium dialysis studies of the binding of thyroxine by human serum albumin have been undertaken to investigate the features of the molecular structure of thyroxine necessary for the interaction. Competition studies were carried out to observe the diminution in the binding of $\mathrm{I}^{131}$ labeled thyroxine caused by the addition of various nonradioactive compounds.

2. The diphenyl ether (thyronine) structure was found to be essential in view of the weak interaction of albumin with all compounds containing a single aromatic ring.

3. The presence of four iodine atoms was optimal for binding, as established by studies revealing weaker binding where iodine atoms were lacking or replaced by other groups.

4. In addition to the requirement of the dissociated (anionic) phenolic hydroxyl group of thyroxine, the alanine side chain, and particularly its carboxyl group, were found to be essential for the firmest binding.

5. In the binding of thyroxine, it is considered likely that cationic groups on the albumin molecule may interact with the phenolate group of thyroxine and also with the carboxyl group of its alanine side chain. The strongest interaction requires the thyronine structure with appropriately situated iodine atoms, thus indicating highly specific albumin-binding sites.

\section{Acknowledgments}

The author wishes to express gratitude to Dr. J. L. Oncley for his interest and help throughout the course of the investigation; to Dr. DeWitt S. Goodman for advice on mathematical formulations; and to Drs. Solomon A. Berson, Herbert G. Rose, and Jack H. Oppenheimer for critical reviews of the manuscript.

\section{Appendix}

The nonradioactive L-thyroxine was purchased from Mann Research Laboratories, New York, N. Y., and, in a few instances, from Sigma Chemical Company, St. Louis, Mo. A number of nonradioactive compounds with a single aromatic ring were obtained from these suppliers and from Hoffmann-LaRoche, Nutley, N. J. Triiodo-L-thyronine and 3,5-diiodo-DL-thyronine were purchased from Mann. DL-Thyronine was purchased from California Corporation for Biochemical Research, New York, N. Y. Monoiodo-L-tyrosine was purchased from Sigma.

In addition, analogues of thyroxine were kindly made available by the Warner-Lambert Research Institute, Morris Plains, N. J. (research affiliate of WarnerChilcott Laboratories), the Smith, Kline \& French Laboratories, Philadelphia, $\mathrm{Pa}$., and by The Squibb Institute for Medical Research, New Brunswick, N. J. Dr. Donald F. Tapley kindly supplied a large number of analogues from Warner-Lambert. A list of the suppliers and the compounds kindly provided follows: WarnerLambert Research Institute-3,5,3'triiodothyropropionic acid, tetraiodothyroacetic acid, tetraiodothyroformic acid, thyroxamine, L-thyroxine O-methyl ether (methoxy-Lthyroxine), 3-monoiodo-DL-thyronine, and tetrachloro-DLthyronine; Smith, Kline \& French Laboratories-3,5,3'triiodo-L-thyronine, 3'-isopropyl-3,5-diiodo-L-thyronine, 3,5diiodo-DL-thyronine, DL-thyronine, D-thyroxine, L-thyroxine, tetraiodothyropropionic acid, tetraiodothyroacetic acid, and thyroxamine; The Squibb Institute for Medical Research-L-thyroxine O-methyl ether (methoxy-L-thyroxine).

Dr. Jacob Robbins of the National Institutes of Health was kind enough to send a supply of thyroxamine provided by Smith, Kline \& French Laboratories and, in addition, the following three compounds provided for him by Glaxo Laboratories, Middlesex, England: 3',5'-dinitro3,5-diiodo-L-thyronine, tetranitro-DL-thyronine, and $N$ acetyl-4'acetoxy-methyl ketone derivative of thyroxine (all groups blocked).

L-Thyroxine O-methyl ether (methoxy-L-thyroxine) was supplied by the following four sources: WarnerLambert Research Institute; The Squibb Institute for Medical Research; Dr. Rosalind Pitt-Rivers, National Institute for Medical Research, Mill Hill, London; and Dr. Victor M. Trikojus, University of Melbourne, Australia.

Thyroxamine supplied by both Warner-Lambert and Smith, Kline \& French appeared to be identical. In no instance did compounds from different sources show detectable differences in behavior with respect to their binding by albumin.

\section{References}

1. Sterling, K., and A. Hegedus. Measurement of free thyroxine concentration in human serum. J. clin. Invest. 1962, 41, 1031. 
2. Sterling, K., and M. Tabachnick. Determination of the binding constants for the interaction of thyroxine and its analogues with human serum albumin. J. biol. Chem. 1961, 236, 2241.

3. Sterling, K., P. Rosen, and M. Tabachnick. Equilibrium dialysis studies of the binding of thyroxine by human serum albumin. J. clin. Invest. 1962, 41, 1021.

4. Robbins, J., and J. E. Rall. The interaction of thyroid hormones and protein in biological fluids. Recent Progr. Hormone Res. 1957, 13, 161.

5. Lein, A. Thyroxine binding by bovine serum albumin (abstract). Fed. Proc. 1952, 11, 91.

6. Sterling, K. Further studies on the interaction between thyroxine and human serum albumin. To be published.

7. Tritsch, G. L., C. E. Rathke, N. E. Tritsch, and C. M. Weiss. Thyroxine binding by human serum albumin. J. biol. Chem. 1961, 236, 3163.

8. Tritsch, G. L., and N. E. Tritsch. Thyroxine binding. II. The nature of the binding site of human serum albumin. J. biol. Chem. 1963, 238, 138.

9. Tabachnick, M. Thyroxine-protein interactions. I. Binding of thyroxine to human serum albumin and modified albumins. J. biol. Chem. 1964, 239, 1242.

10. Steiner, R. F., J. Roth, and J. Robbins. Thyroxine binding by serum albumin measured by fluorescence quenching (abstract). The Endocrine Society Annual Meeting, June 17-20, 1964. San Francisco, Calif.

11. Tabachnick, M., and N. A. Giorgio, Jr. Thyroxineprotein interactions. II. The binding of thyroxine and its analogues to human serum albumin. Arch. Biochem., in press.
12. Klotz, I. M., and F. M. Walker. The binding of organic ions by proteins. Charge and $\mathrm{pH}$ effects. J. Amer. chem. Soc. 1947, 69, 1609.

13. McMenamy, R. H., and J. L. Oncley. The specific binding of L-tryptophan to serum albumin. J. biol. Chem. 1958, 233, 1436.

14. Goodman, D. S. The interaction of human serum albumin with long-chain fatty acid anions. J. Amer. chem. Soc. 1958, 80, 3892.

15. Scatchard, G. The attractions of proteins for small molecules and ions. Ann. N. Y. Acad. Sci. 1949, $51,660$.

16. Scatchard, G., W. L. Hughes, Jr., F. R. N. Gurd, and P. E. Wilcox. The interaction of proteins with small molecules and ions in Chemical Specificity in Biological Interactions, F. R. N. Gurd, Ed. New York, Academic Press, 1954, p. 193.

17. Scatchard, G., J. S. Coleman, and A. L. Shen. Physical chemistry of protein solutions. VII. The binding of some small anions to serum albumin. J. Amer. chem. Soc. 1957, 79, 12.

18. Edsall, J. T., and J. Wyman. Biophysical Chemistry. New York, Academic Press, 1958, vol. 1, p. 652.

19. Wolff, J., M. E. Standaert, and J. E. Rall. Thyroxine displacement from serum proteins and depression of serum protein-bound iodine by certain drugs. J. clin. Invest. 1961, 40, 1373.

20. Ingbar, S. H. Observations concerning the binding of thyroid hormones by human serum prealbumin. J. clin. Invest. 1963, 42, 143.

21. Hughes, W. L., Jr. Plasma proteins in The Proteins, H. Neurath and K. Bailey, Eds. New York, Academic Press, 1953, vol. II, part B, p. 663.

\section{NOTICE TO AUTHORS}

Beginning with papers accepted January 1, 1965, THE JOURNAL OF CLINICAL INVESTIGATION will charge $\$ 10.00$ per page for each article published, provided that the author's research funds or the institution that supported the research can bear this cost. 